\title{
Face(book)ing the Truth: Initial Lessons Learned using Facebook Advertisements for the Chatbot-delivered Elena+ Care for COVID-19 Intervention
}

\author{
Joseph Ollier ${ }^{1} \mathbb{C}^{\mathrm{a}}$, Prabhakaran Santhanam ${ }^{2} \mathbb{0}^{\mathrm{b}}$ and Tobias Kowatsch ${ }^{2,3} \mathbb{B}^{\mathrm{c}}$ \\ ${ }^{1}$ Center for Digital Health Interventions, Chair of Technology Marketing, \\ Department of Technology, Management, and Economics, ETH Zurich, Zurich, Switzerland \\ ${ }^{2}$ Center for Digital Health Interventions, Department of Technology, Management, and Economics, \\ ETH Zurich, Zurich, Switzerland \\ ${ }^{3}$ Center for Digital Health Interventions, Institute of Technology Management, St. Gallen, Switzerland \\ jollier@eth.ch,psanthanam@ethz.ch,tkowatsch@ethz.ch
}

Keywords: Facebook Advertisements, Social Media, Digital Health, Chatbots, Elena+ Care for COVID-19.

\begin{abstract}
Utilizing social media platforms to recruit participants for digital health interventions is becoming increasingly popular due to its ability to directly track advertising spend, number of app downloads and other metrics transparently. The following paper concerns the initial tests completed on the Facebook Ad Manager platform for the chatbot-delivered digital health intervention Elena+ Care for COVID-19. Eleven advertisements were run in the UK and Ireland during August/September 2020, with resulting downloads, post (i.e. advert) reactions, post shares and other advertisement engagement metrics tracked. Key findings from our advertising campaigns highlight that: (i) static images with text function better than carousel of images, (ii) Android users download and exhibit greater engagement behaviors than iOS users, and (iii) middle-aged and older women have the highest number of downloads and the most engaged behaviors (i.e. reacting to posts, sharing posts etc.). Lessons learned are discussed considering how other designers of digital health interventions may benefit and learn from our results when trialing and running their own ad campaigns. It is hoped that such discussions will be beneficial to other health practitioners seeking to scale-up their digital health interventions widely and reach individuals in need.
\end{abstract}

\section{INTRODUCTION}

Social media platforms are becoming an increasingly advantageous route to recruit participants for health interventions (Arigo et al., 2018). They are particularly helpful in digital interventions utilizing smartphone technology whereby the tracking of downloads from advertisements is easily facilitated and costs per new participant measured (Platt et al., 2016). The following paper overviews the preliminary testing campaigns for the Elena + Care for COVID-19 (www.elena.plus) digital health intervention, which offers chatbot-led digital coaching on various facets of an individual's lifestyle and health promoting behaviors (e.g. sleep, mental health, physical activity etc.) that may be under increased strain during the COVID-19 pandemic (Ollier, Joseph \& Kowatsch, 2020). It is hoped that be demonstrating early lessons learned from early testing campaigns, individuals running future campaigns may be able to identify relevant patterns earlier and save funding for more cost-effective advertisements to help individuals in need.

The paper continues then by overviewing the rising importance of social media in recruiting for digital health interventions, and discussing the app used for recruitment, Elena+ Care for COVID-19. Following this we explain the methodological framework and continue by exploring data exported from the Facebook Ad Manager Platform. Lastly, we conclude with lessons learned and future

a(D) https://orcid.org/0000-0001-8603-0793

b(iD) https://orcid.org/0000-0002-9506-4888

c(i) https://orcid.org/0000-0001-5939-4145 
considerations for other designers of digital health interventions.

\section{BACKGROUND}

\subsection{Social Media Recruitment}

In scaling up digital health interventions, and after the hard work of designing, implementing and testing a digital product, comes the next challenge of successful recruitment (Arigo et al., 2018; Platt et al., 2016). This challenge is often given less thought in planning stages, however, and less focus in academic research. A cursory search of Google Scholar with the term "digital health intervention", for example, returns a huge 2440000 search results, however when simply adding the additional word "recruitment" at the end of the search term only 154000 search results are found, and when "social media recruitment" is added a comparably measly 136000 search results are found. Therefore despite the importance of successful recruitment strategies for health interventions, social media recruitment is a relatively neglected area in healthcare research.

Recruitment success is vital however for all interventions, and particularly those aimed at population level health concerns such as obesity (Chou et al., 2014), mental health (Sanchez et al., 2020), alcoholism (Wozney et al., 2019) or the current paper's example Elena+ Care for COVID-19 (Ollier, Joseph \& Kowatsch, 2020). Recruitment in such contexts is vital to generate enough participants to both help the public at large through cutting edge science as well as power statistical analyses which can analyze efficacy. Additionally, for other health interventions which target a smaller population group and have patient access granted via a medical organization, following up on initial success in an academic setting with wider recruitment will likely be a vital part of the marketing mix in translating a promising study to a digital start up's new digital product (World Health Organization, 2009).

As the proportion of spending on social media versus traditional media has been generally rising (Ma \& Du, 2018) as marketing practice has utilized and adapted segmenting, targeting and positioning to better effectiveness with social media platforms (Canhoto et al., 2013; Kotler et al., 2016) for healthcare researchers the highly utilizable nature of social media is becoming an increasingly attractive recruitment route. It offers more focused targeting and opens the door for cost-effective recruitment of participants independent of medical organizations, which may be particularly valuable in scaling up digital health intervention ideas into real products actively recruiting participants (World Health Organization, 2009).

\subsection{Elena+ Care for COVID-19}

The Elena+ digital health intervention is one such example of an emerging digital product scaling up with the use of social media advertisements for recruitment. Elena+ (Ollier, Joseph \& Kowatsch, 2020) was developed by a group of researchers during Spring 2020 as the COVID-19 pandemic spread across the globe. It utilizes a chatbot embedded smartphone application to address the collateral damage of social distancing and lockdowns i.e. that health promoting behaviors within individual's lifestyles may be under increased strain (Javed et al., 2020). Therefore, the chatbot offers 43 coaching sessions focusing on psychoeducational training and activities in the fields of: COVID-19 information, physical activity, sleep, anxiety, loneliness, mental resources and diet and nutrition. The core recruitment strategy for Elena + was based upon Facebook advertisements, of which findings from preliminary experimentations are presented in this paper.

\section{METHODOLOGY}

During August-September 2020 advertisements were created and displayed using the Facebook $\mathrm{Ad}$ Manager platform for Facebook Businesses. A variety of advertisements were tested which were either (i) static images with text or (ii) a carousel of images. Advertisements were run on both $\mathrm{OOS}$ and Android smartphone operating systems and for users within UK and Ireland in English only, with relevant links to the app store included on the advertisements and Facebook API for developers implemented so that downloads resulting from the link click could be tracked.

In total eleven advertisements were ran online, of which; (i) eight were of static image with text type (Figure 1) and three were carousel of images type (Figure 2); (ii) seven were aimed at iOS users and four at Android users; (iii) three were in the UK and eight were in Ireland. Each advertisement was run for up to one week, with a budget of circa 11 USD (10 CHF) per day. Various metrics were collected by the Facebook Ad Manager platform, and for the current analyses we looked at downloads as the primary result of interest, however, other engagement related metrics for the advertisement (post engagement, page 
engagement, post reactions, post shares) were also downloaded from the platform. Descriptive statistics were calculated to outline the relative performance of these advertisements

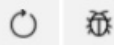

Elena+ Care for COVID-19 Sponsored $\cdot$ a

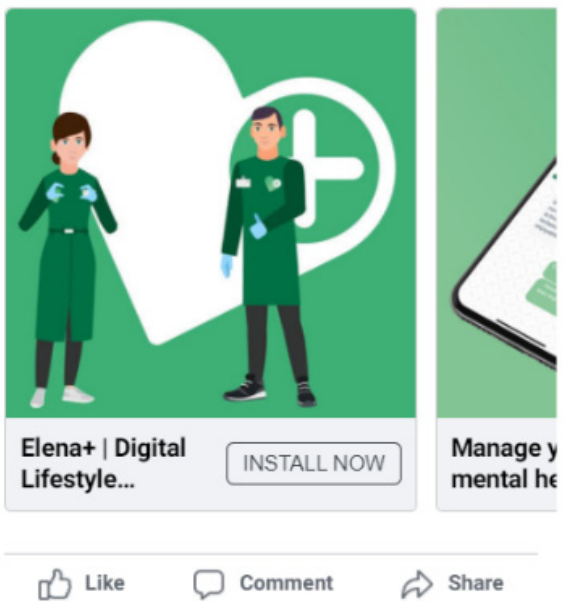

Figure 1: Static Image with Text Advertisement.

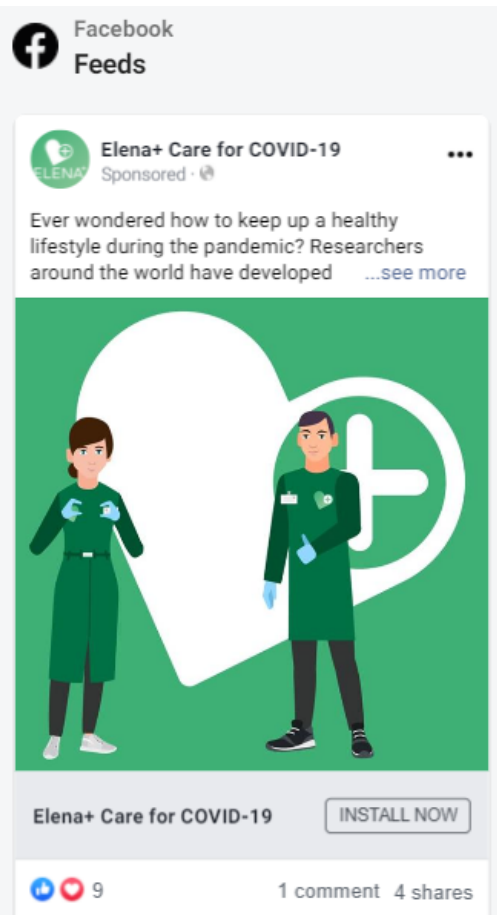

Figure 2: Carousel of Images Advertisement.

\section{RESULTS}

All advertisements ran on Facebook between $13^{\text {th }}$ August to $22^{\text {nd }}$ September 2020, with a resulting 186 downloads at a cost of 463.24 CHF (approx. 507 USD). Although we specified a guideline budget of 10 CHF per day and to pay "cost per result" (i.e. by downloads) some variation occurred due to increased advertisement engagement (as Facebook states may occur in their website documentation). Advertisements typically ran for one week; however, due to requirements of the Elena+ project (e.g. maintenance tasks) outside the scope of this paper, some fluctuations occurred. A summary can be seen below of each advertisement, the total number of days it ran, and total budget spent.

Table 1: Advertisement Summary.

\begin{tabular}{|c|c|c|}
\hline Advert name & Days & Cost \\
\hline Ireland Static 01 $($ Android) & 7 & 70.40 \\
\hline Ireland Static 02 $($ Android) & 7 & 76.22 \\
\hline UK Static 01 $($ Android) & 7 & 59.37 \\
\hline UK Static 02 $($ Android) & 7 & 75.74 \\
\hline UK Static 01 $($ iOS $)$ & 7 & 60.38 \\
\hline Ireland Static 01 $($ iOS $)$ & 3 & 3.98 \\
\hline Ireland Static 02 $($ iOS $)$ & 5 & 38.32 \\
\hline Ireland Static 03 $(i O S)$ & 5 & 35.96 \\
\hline Ireland Carousel 01 $($ iOS $)$ & 5 & 32.30 \\
\hline Ireland Carousel 02 $($ iOS $)$ & 3 & 2.10 \\
\hline Ireland Carousel 03 $(i O S)$ & 4 & 3.98 \\
\hline
\end{tabular}

\subsection{Elena+ App Downloads}

Firstly, looking at simple comparisons between the types of advertisements run, the static image with text advertisement functioned much better than using a carousel of images with regard to downloads.

Figure 3 shows that from the three carousel advertisements run on $\mathrm{iOS}$ only one download resulted. Whereas for the eight static image with text advertisements (which were ran on both $\mathrm{iOS}$ and Android) resulted in 185 downloads. When considering the average ad return for downloads (i.e. no. of downloads divided by no. of advertisements used, hereafter referred to as AAR), static image with text resulted in 23.125 users per ad, whereas carousel ad only 0.33 users per ad. 


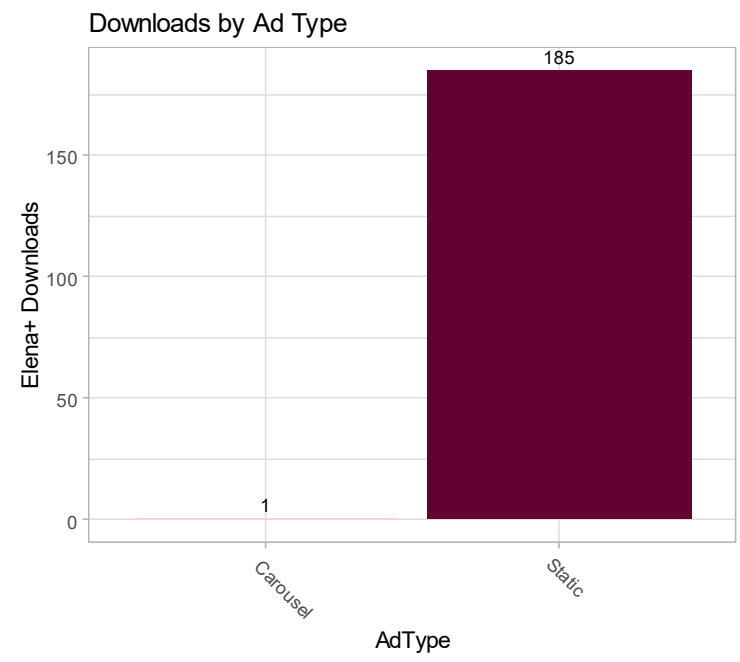

Figure 3: Downloads by Advertisement Type.

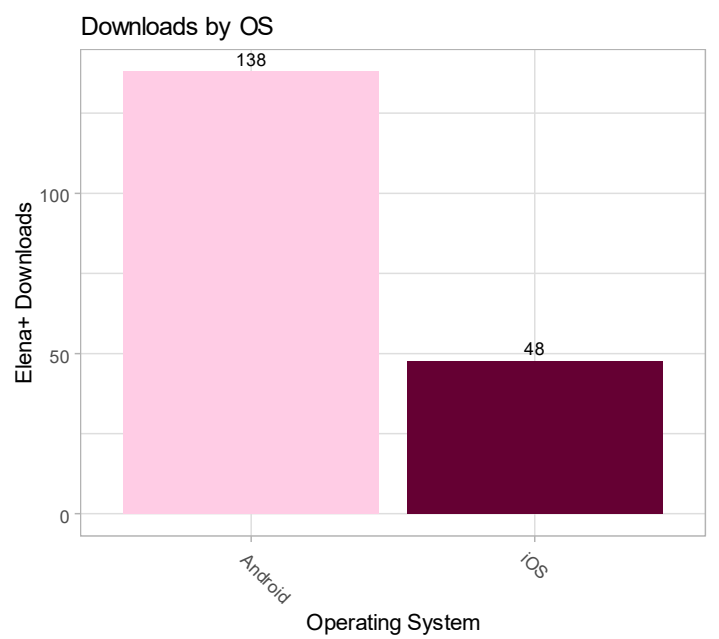

Figure 4: Downloads by Operating System.

When making a simple comparison between operating system of the seven advertisements aimed at iOS users and four advertisements at Android users, Figure 4 shows that running advertisements on Android resulted in much higher numbers of downloads. From the seven advertisements aimed at iOS users, 48 downloads resulted (AAR of 6.857) whereas for Android it was much higher (AAR of 34.5).

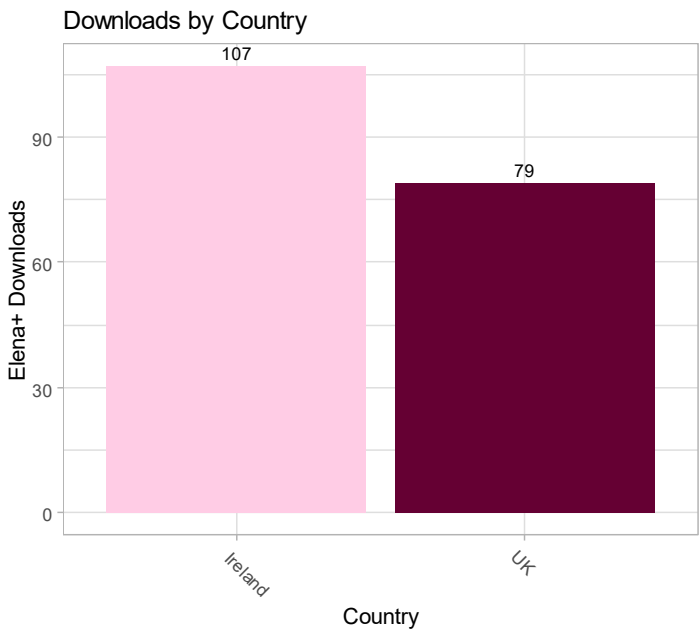

Figure 5: Downloads by Country.

A simple comparison by country in Figure 5 shows that the eight advertisements in Ireland resulted in 107 downloads (AAR of 13.375) whereas the three advertisements in the U.K. resulted in 79 downloads (AAR of 26.333). Figure 6 also shows gender and age of downloads, whereby females aged more than 35 years are downloading the app in greater numbers.

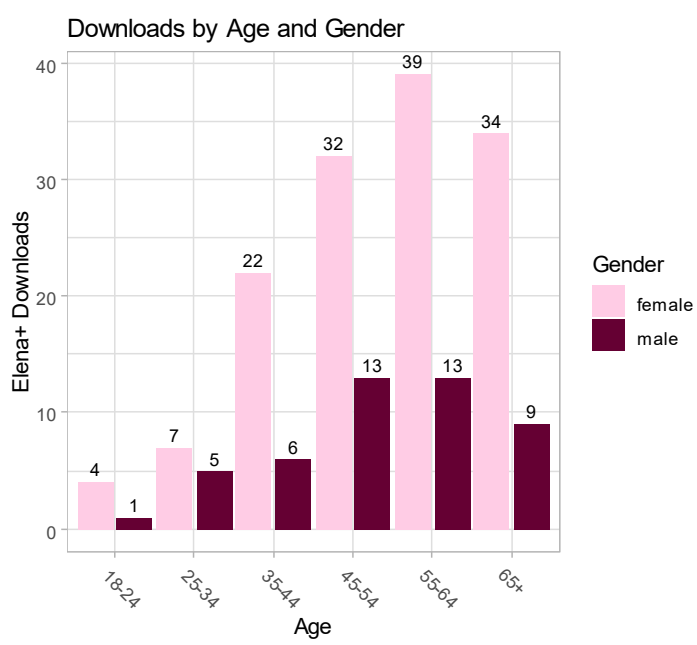

Figure 6: Downloads by Age and Gender.

A summary of number of downloads for all factors discussed above is shown below for Ireland (Figure 7) and the U.K (Figure 8). 


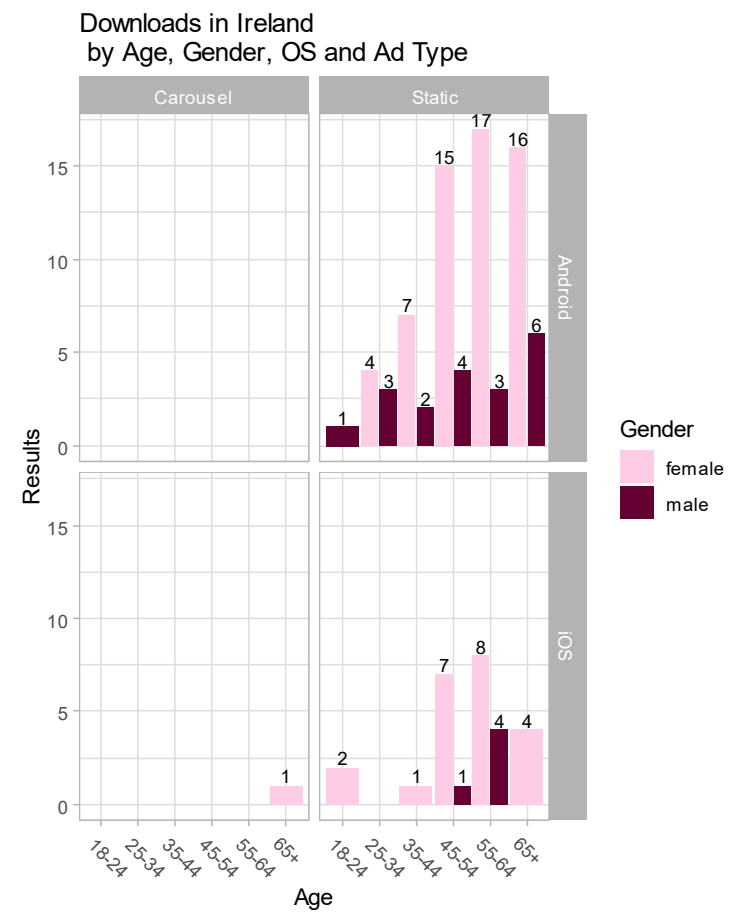

Figure 7: Downloads by Ad Type, Operating System, Age and Gender in Ireland.

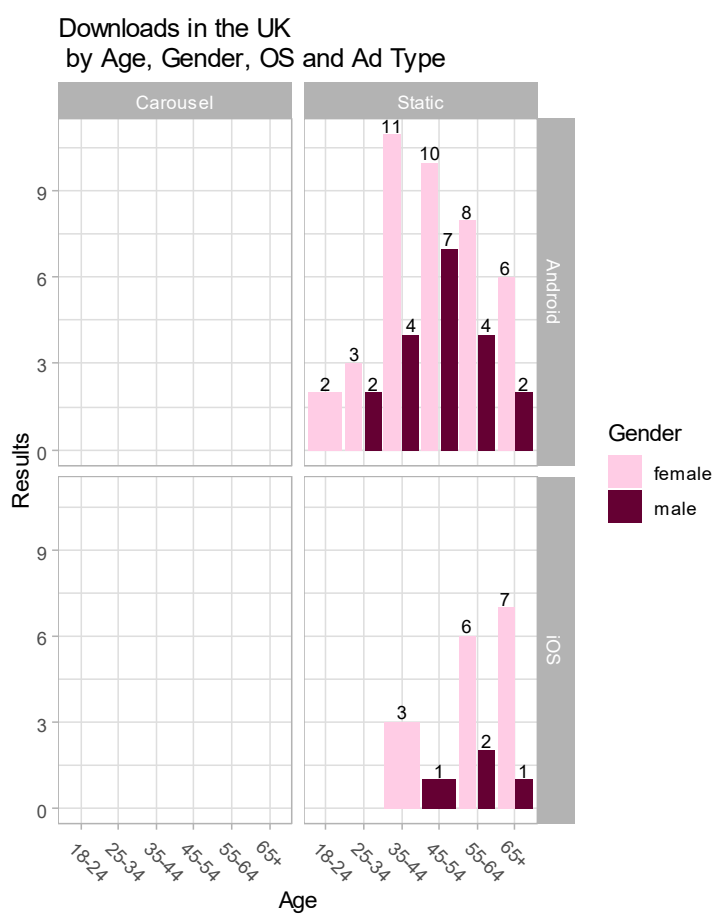

Figure 8: Downloads by Ad Type, Operating System, Age and Gender in in the U.K.

\subsection{Advertisement Engagement Metrics}

To complement the above findings a brief summary of advertisement engagement metrics is provided in this section overviewing how the advertisements also affected a few selected promotional metrics. These include: (i) post engagement, (ii) page engagement, (iii) post reactions, and (iv) post shares.

Post engagement is defined by Facebook as "all actions people take involved your ads" such as "reacting to, commenting on or sharing the ad, claiming an offer, viewing a photo or video, or clicking on a link.”. Facebook defines this as a useful measure to see how relevant the advertisements were to the recipients.

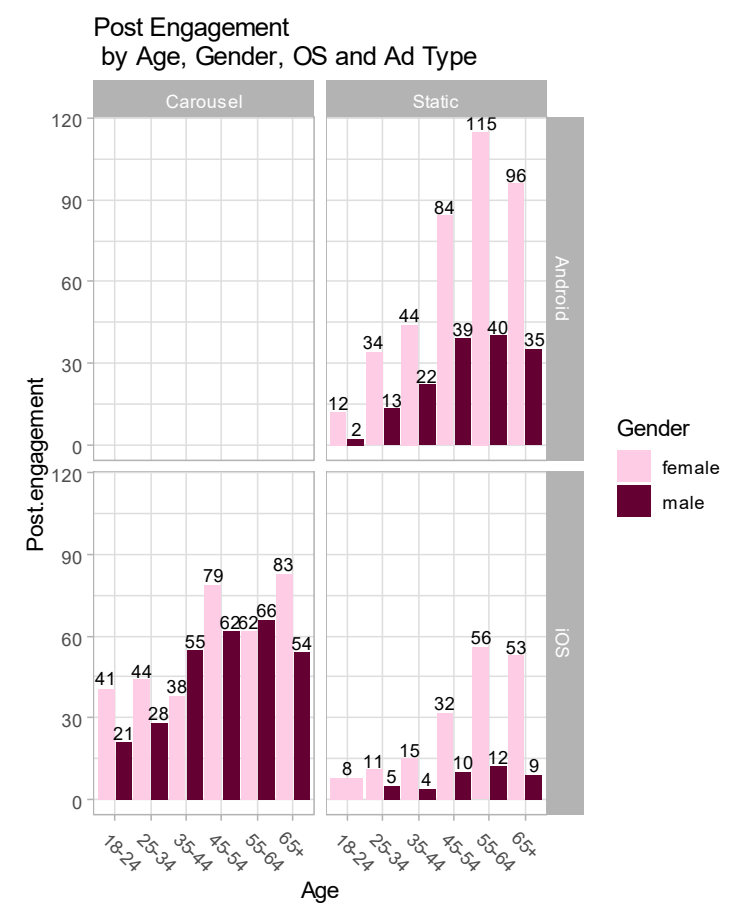

Figure 9: Post engagement by Age, Gender, OS and Ad Type.

As can be seen in Figure 9, middle-aged and older women have the highest total summed quantity of post engagement. Static Android advertisements drive best post engagement, as no carousel advertisements were run on Android, comparison is not possible however.

Page engagement includes "interactions with your Facebook Page and its posts" and actions such as "liking your Page, reacting with 'Love' to a post, checking in to your location, clicking a link and more.". As with post engagement, Facebook notes page engagement as a useful metric to see how 
relevant the advertisements were to the given audience.

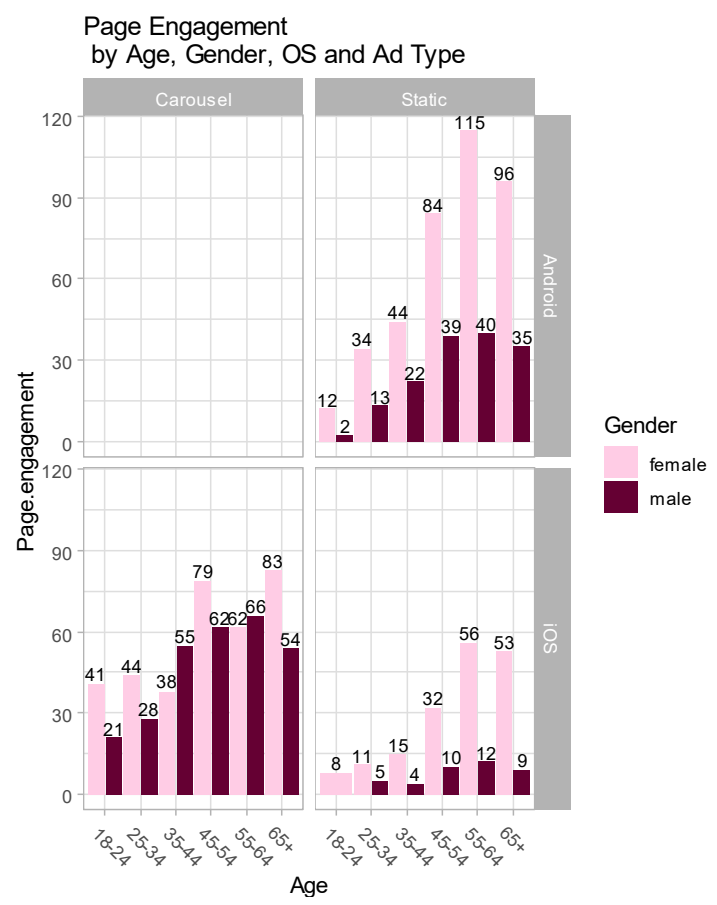

Figure 10: Page engagement by Various Factors.

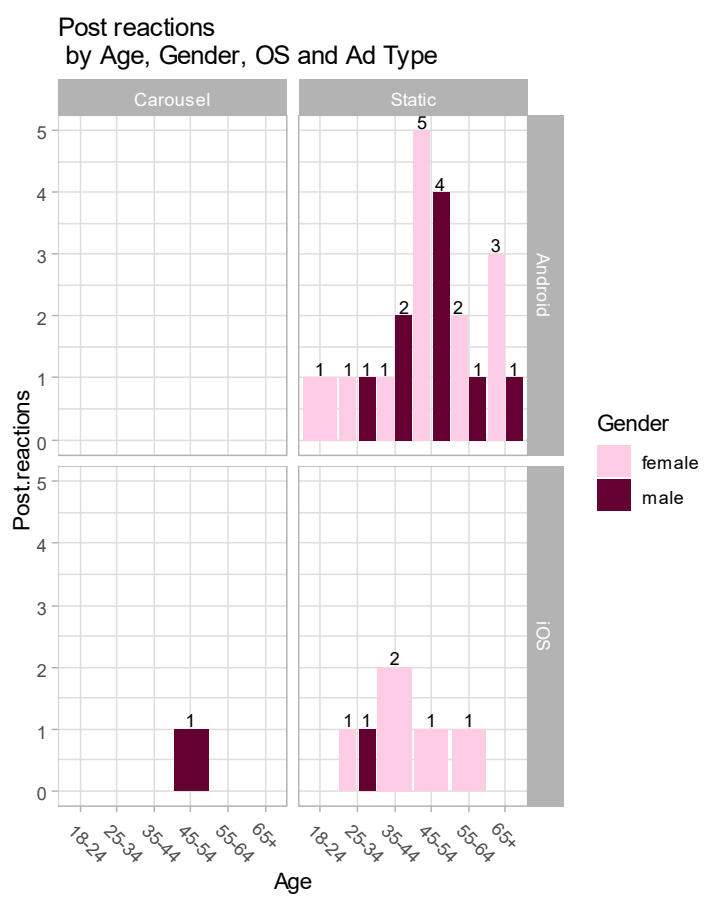

Figure 11: Post reactions by Various Factors.
The summed total on page engagement (Figure 10 ) is highest again for static Android advertisements, and women from $35+$ years again exhibit the highest engagement.

Post reactions includes all types of reactions to an ad, such as reacting with "like, love, haha, wow, sad or angry.". Facebook states that this helps advertisements perform better, as individuals automatically start to follow updates related to the ad (i.e. new comments, reactions etc.) which can drive further engagement with a business page and content. As can be seen in Figure 11, post reactions are once more best performing for static advertisements on Android, and at least for Android users, the aforementioned pattern of middle-aged and above women scoring highest appears to be exhibited.

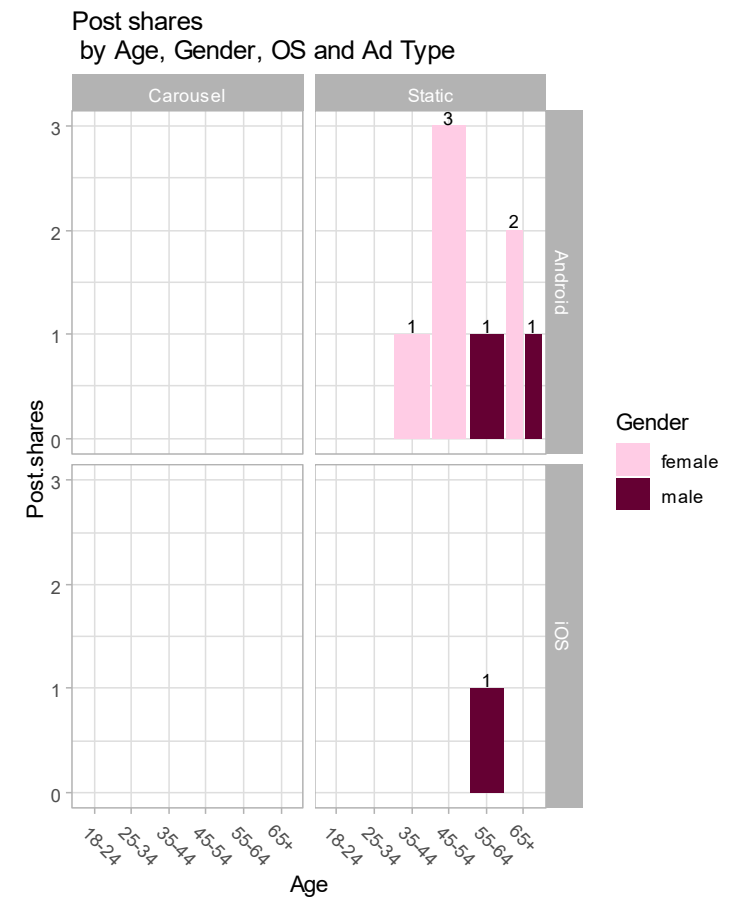

Figure 12: Post shares by Various Factors.

Post shares includes whether individuals share the advertisement, for example on their or others' timelines, in groups, on other pages etc. However, it does not measure any subsequent engagement after that point (for example, comments on shared posts, or whether individuals that see the shared post navigate to the original ad and take any actions). Similar to previous results, Figure 12 indicates that general middle-aged and older females are primarily sharing the advertisements based on available results thus far. 


\section{DISCUSSION}

Our findings have highlighted that Android users are more responsive to the advertisements in terms of both downloads, the primary metric of interest, as well as engagement metrics. This shows that Android may be a more cost-effective platform as more results were found directly from the advertisements themselves, and via their higher engagement, Android users effectively market the app further to their contacts via their greater activity and interactions with both the advertisements and the Elena + Facebook page. It is possible therefore that Android users as a whole are less data privacy sensitive, and thus interact more. This may be likely, as Android phones can range from relatively cheap to very expensive when bought firsthand and brand new, whereas iOS models are always relatively expensive. As income level is indicative of education (Tolley \& Olson, 1971), and higher digital literacy results in more privacy protective behaviors (Park, 2011), it may be due to less affluent/less educated individuals being represented amongst Android users.

Regarding the prevalence of middle-aged aged and above females being primary downloaders and those exhibiting engaged behaviors, the authors feel that this perhaps is related to either the ad or app content. It may be simply that men and youth found the simple advertisements we used less attractive, as these groups, stereotypically, exhibit greater affinity to new technology and technological devices (Olson et al., 2011; Venkatesh \& Morris, 2000). Thusly, for targeting youth or men, perhaps better ad content (media, text) was required. Alternatively, however, it may simply represent that middle-aged and older women are a particular at-risk group for the intervention used in this study i.e. Elena+ Care for COVID-19. Often middle-aged and older women are responsible for care roles in the family (Dahlberg et al., 2007) (i.e. caring for children, caring for elderly relatives or both), and may also still be in employment. Adding the additional strain of the pandemic and social distancing/isolation requirements on top of all other respective duties could therefore disproportionally affect the group of middle-aged women and could be an alternative explanation as to why they downloaded/engaged most often after being exposed to advertising.

\section{CONCLUSIONS}

In summary these preliminary findings from the Facebook advertising campaigns are not to be taken as definitive proof due to the relatively small budget and duration of the campaigns and the fact that there are likely many variations of success contingent on the medical intervention being utilized and patient population. However, it is hoped that by sharing our findings on utilizing social media for driving downloads of app, Elena+ Care for COVID-19, others may benefit and that needless costs are not duplicated by repeatedly running trial and error advertising campaigns to find what works best, and may enable practitioners to draw meaningful conclusions in their own fields more speedily, saving budget for reaching potential beneficiaries of their digital health interventions.

\section{REFERENCES}

Arigo, D., Pagoto, S., Carter-Harris, L., Lillie, S. E., \& Nebeker, C. (2018). Using social media for health research: Methodological and ethical considerations for recruitment and intervention delivery. Digital Health, 4 , https://doi.org/10.1177/2055207618771757 205520761877175

Canhoto, A. I., Clark, M., \& Fennemore, P. (2013). Emerging segmentation practices in the age of the social customer. Journal of Strategic Marketing, 21(5), 413-428. https://doi.org/10.1080/0965254X.2013.801609

Chou, W. S., Prestin, A., \& Kunath, S. (2014). Obesity in social media: a mixed methods analysis. Translational Behavioral Medicine, 4(3), 314-323. https://doi.org/10.1007/s13142-014-0256-1

Dahlberg, L., Demack, S., \& Bambra, C. (2007). Age and gender of informal carers: A population-based study in the UK. Health and Social Care in the Community, 15(5), 439-445. https://doi.org/10.1111/j.13652524.2007.00702.x

Javed, B., Sarwer, A., Soto, E. B., \& Mashwani, Z.-R. (2020). Impact of SARS-CoV-2 (Coronavirus) Pandemic on Public Mental Health. Frontiers in Public Health, 8 ,

292. https://doi.org/10.3389/fpubh.2020.00292

Kotler, P., Kartajaya, H., \& Setiawan, I. (2016). Marketing 4.0: Moving from traditional to digital. John Wiley \& Sons.

Ma, J., \& Du, B. (2018). Digital advertising and company value: Implications of reallocating advertising expenditures. Journal of Advertising Research, 58(3), 326-337. https://doi.org/10.2501/JAR-2018-002

Ollier, Joseph \& Kowatsch, T. (2020). Elena + Care for COVID Website. 2020. elena.plus 
Olson, K. E., O'brien, M. A., Rogers, W. A., Charness, N., Olson, K. E., Rogers, W. A., O'brien, M. A., \& Charness, N. (2011). Diffusion of Technology: Frequency of use for Younger and Older Adults. Ageing Int, 36, 123-145. https://doi.org/10.1007/s12126-0109077-9

Park, Y. J. (2011). Digital Literacy and Privacy Behavior Online. Communication Research, 40(2), 215-236. https://doi.org/10.1177/0093650211418338

Platt, T., Platt, J., Thiel, D. B., \& Kardia, S. L. R. (2016). Facebook Advertising Across an Engagement Spectrum: A Case Example for Public Health Communication. JMIR Public Health and Surveillance, 2(1), e27. https://doi.org/10.2196/publichealth.5623

Sanchez, C., Grzenda, A., Varias, A., Widge, A. S., Carpenter, L. L., McDonald, W. M., Nemeroff, C. B., Kalin, N. H., Martin, G., Tohen, M., Filippou-Frye, M., Ramsey, D., Linos, E., Mangurian, C., \& Rodriguez, C. I. (2020). Social media recruitment for mental health research: A systematic review. Comprehensive Psychiatry, 103, 152197. https://doi.org/10.1016/j.comppsych.2020.152197

Tolley, G. S., \& Olson, E. (1971). The interdependence between income and education. Journal of Political Economy, 79(3), 460-480.

Venkatesh, V., \& Morris, M. G. (2000). Why Don't Men Ever Stop to Ask for Directions? Gender, Social Influence, and Their Role in Technology Acceptance and Usage Behavior. MIS Quarterly, 24(1), 115-139. https://doi.org/10.2307/3250981

World Health Organization. (2009). Practical guidance for scaling up health service innovations.

Wozney, L., Turner, K., Rose-Davis, B., \& McGrath, P. J. (2019). Facebook ads to the rescue? Recruiting a hard to reach population into an Internet-based behavioral health intervention trial. Internet Interventions, 17, 100246. https://doi.org/10.1016/j.invent.2019.100246 